\title{
Pharmacological Modulation by Shakuyakukanzoto (Shao-Yao-Gan-Cao-Tang) and the Ingredients in Rat Intestinal Smooth Muscle
}

\author{
Hiroyasu Satoh, Kiminori Tsuro \\ Department of Pharmacology, Traditional Herbal Medicine, School of Medicine, \\ Nara Medical University, Kashihara, Japan \\ E-mail: hysat@naramed-u.ac.jp \\ Received January 21, 2011; revised March 10, 2011; accepted May 24, 2011
}

\begin{abstract}
Shakuyakukanzoto (Shao-Yao-Gan-Cao-Tang), a formulation of Japanese herbal (Kampo) medicines, is composed of Paeoniae Radix and Glycyrrhizae Radix. Effects of Shakuyakukanzoto and the ingredients on rat intestinal tract were examined. Shakuyakukanzoto $(0.01-0.3 \mathrm{mg} / \mathrm{ml})$ relaxed a carbachol $(\mathrm{CCh}, 0.3 \mu \mathrm{M})$ -induced contraction in a concentration-dependent manner. Both components (Paeoniae Radix and Glycyrrhizae Radix) also relaxed the CCh-induced contraction. At 0.1 to $1 \mathrm{mM}$, their constituents (paeoniflorin and glycyrrhetic acid) and the metabolic products (18- $\alpha$ - and 18- $\beta$-glycyrrhetinic acids) exerted almost the same actions. The relaxations induced by Shakuyakukanzoto were not modified by $1 \mu \mathrm{M}$ nicardipine, $10 \mu \mathrm{M}$ suramin (ATP receptor inhibitor) and several $\mathrm{K}^{+}$channel inhibitors, but was attenuated by $20 \mu \mathrm{M}$ IBMX (a phosphodiesterase inhibitor). Also, IBMX inhibited the relaxations induced by paeoniflorin and glycyrrhetic acid, but not by other ingredients. Nicardipine decreased the relaxation of just 18 - $\alpha$-glycyrrhetinic acid. Even in non-treatment with CCh, Shakuyakukanzoto relaxed the intestinal tract. CCh $(0.3 \mu \mathrm{M})$ elicited spontaneous contractions in 23\% specimens, depressed by application of Shakuyakukanzoto. These results indicate that Shakuyakukanzoto causes a remarkable relaxation by the anti-cholinergic and the PDE inhibitory actions, but by minor contribution of $\mathrm{Ca}^{2+}$ channel inhibition. Thus, Shakuyakukanzoto exerts an anti-spasmodic action due to the interaction with pharmacological effects of its ingredients.
\end{abstract}

Keywords: Shakuyakukanzoto, Paeoniae Radix, Paeoniflorin, Glycyrrhetic Acid, PDE Inhibition, Anti-Cholinergic Action, $\mathrm{Ca}^{2+}$ Channel Inhibition, Intestinal Tract

\section{Introduction}

Since traditional Japanese herbal (Kampo) medicines are composed of a mixture with lots of herbs, they produce multiple pharmacological and physiological functions. Shakuyakukanzoto (Shao-Yao-Gan-Cao-Tang), a kind of Kampo formulations, is composed of just two components; Paeoniae Radix and Glycyrrhizae Radix. The main ingredient of Paeoniae Radix is paeoniflorin, and that of Glycyrrhizae Radix is glycyrrhetic acid.

Shakuyakukanzoto has been mostly used for the relaxant effect of skeletal muscle [1]. Nicotinic ACh receptors on neuromuscular junction play an important role for the contraction. Paeoniflorin produced the relaxation by means of a depolarized blockade like succinylcholine [2]. Paeoniflorin regulates $\mathrm{Ca}^{2+}$ movement near around neuromuscular junction, and glycyrrhetic acid inhibits $\mathrm{Ca}^{2+}$-activated $\mathrm{K}^{+}\left(\mathrm{I}_{\mathrm{KCa}}\right.$ ) channel to repolarize or hyperpolarize the membrane [3]. The combination with Paeoniae radix and Glycyrrhizae radix enforces the relaxant action of skeletal muscle.

Also, Shakuyakukanzoto may be useful to relieve a pain, and exhibit an anti-spasmodic action in gastrointestinal smooth muscle [4]. The relaxations of smooth muscles induced by Kampo medicines depend on mainly a phosphodiesterase (PDE) inhibition [5]. Most recent reports have also demonstrated to play a key role for regulation of the gap junction on gastrointestinal smooth muscle [6-8].

Until now, there is less information of more detailed pharmacological mechanisms for the gastrointestinal actions of Shakuyakukanzoto, the components (Paeoniae 
Radix and Glycyrrhizae Radix), especially the ingredients (paeoniflorin and glycyrrhetic acid) and the metabolic products (18- $\beta$ - and 18- $\alpha$-glycyrrhetinic acids). In the present experiments, therefore, the pharmacological actions of Shakuyakukanzoto and the ingredients on the relaxation were investigated using rat intestinal smooth muscle.

\section{Material and Methods}

All experiments were carried out, according to the guidelines laid down by the Nara Medical University Animal Welfare Committee, and also under the terms of the Declaration of Helsinki.

\subsection{Experimental Procedures}

Wistar rats (8 to 15 weeks-old), weighing approximately $300 \mathrm{~g}$, were anesthetized with ether, and euthanized by exsanguination. The intestinal tract was quickly removed, and the isolated intestinal tract was cut into rings of $1.5 \mathrm{~cm}$ in length. The strips were suspended in a jacketed organ chamber filled with $20 \mathrm{ml}$ modified Tyrode solution.

The strips were suspended between both sides with stainless steel stirrups. The lower stirrup was anchored and the upper stirrup was attached to a force-displacement transducer (Nihon Kohden TB-652T, Tokyo, Japan) to record the isometric force. All strips were stretched to generate a resting tension of $1.0 \mathrm{~g}$, which was optimal for contractions with muscarinic ACh receptor agonist. After 40 min of resting, carbachol (CCh, $0.3 \mu \mathrm{M}$ ) was added to the tissue bath. After the contractile response became steady, the drugs were cumulatively administrated into the bath solution. The effects of each concentration of the drugs were measured 5 - 7 min after the responses became steady. To examine the involvement with $\mathrm{Ca}^{2+}$ channel, PDE or other mechanisms, the pretreatment with $1 \mu \mathrm{M}$ nicardipine, $20 \mu \mathrm{M}$ IBMX or other inhibitors was carried out. Each of the experiments was examined at least quadruplicates. The responses were analyzed as a percentage change from the value before an application of drugs.

\subsection{Experiments of Spontaneous Contractions}

Pretreatment with CCh $(0.3 \mu \mathrm{M})$ was usually carried out. Under the conditions, the spontaneous contractions were exhibited occasionally in some specimens. The effects of Shakuyakukanzoto on the spontaneous contractions were investigated.

\subsection{Experiments in the Absence of $\mathrm{CCh}$}

Using rat ileum in non-pretreatment with CCh, the ef- fects of Shakuyakukanzoto and the ingredients on gastrointestinal smooth muscle were examined using the same experimental techniques.

\subsection{Solution and Drugs}

The modified Tyrode solution was comprised of (in mM); $136.8 \mathrm{mM} \mathrm{NaCl}, 2.7 \mathrm{mM} \mathrm{KCl}, 1.8 \mathrm{mM} \mathrm{CaCl}_{2}, 1.1 \mathrm{mM}$ $\mathrm{MgCl}_{2}, 0.4 \mathrm{mM} \mathrm{NaH} \mathrm{PO}_{4}, 11.9 \mathrm{mM} \mathrm{NaHCO}$, and 5.6 $\mathrm{mM}$ glucose. The chamber solution was kept at $36.5^{\circ} \mathrm{C}$ and oxygenated with $95 \% \mathrm{O}_{2}$ and $5 \% \mathrm{CO}_{2}$.

The drugs used were Shakuyakukanzoto, Paeoniae Radix and Glycyrrhizae Radix (Tsumura Co., Tokyo, Japan), as a spray-dried powder extracted with boiling water of a ground raw materials. Each drug was dissolved with DMSO. Other drugs used were CCh, $18-\alpha$-glycyrrhetinic acid and 18- $\beta$-glycyrrhetinic acid (Sigma Chemical, MO. U.S.A.), and paeoniflorin and glycyrrhtic acid (Wako Chemical, Kyoto, Japan). Nicardipine $\left(\mathrm{Ca}^{2+}\right.$ channel inhibitor), Bay K $8644\left(\mathrm{Ca}^{2+}\right.$ channel stimulator), suramin (ATP receptor inhibitor), apamin $\left(\mathrm{Ca}^{2+}\right.$-activated $\mathrm{K}^{+}$channel inhibitor), glibenclamide (ATP-sensitive $\mathrm{K}^{+}$channel inhibitor), tetraethyammonium (TEA, voltage-dependent $\mathrm{K}^{+}$channel inhibitor) and 3-isobutyl-1-methylxanthine (IBMX, phosphodiesterase inhibitor) (Sigma) were also used.

\subsection{Statistical Analyses}

To compare the pair values, we are used statistical methods of the Student's $t$-test and ANOVA followed by post-hoc tests (Dunn-Bonferonii test) using Excel (Microsoft Inc., Washington, U.S.A.) and S-PLUS (Mathematical System Inc., Washington, U.S.A.). All values are represented as means \pm SEM. A p value of less than 0.05 was considered significant.

\section{Results}

\subsection{Effects of Shakuyakukanzoto on CCh-Induced Contraction}

Pretreatment with $0.3 \mu \mathrm{M}$ CCh produced a strong contraction of isolated ileum; by $1.4 \pm 0.2 \mathrm{~g}(\mathrm{n}=157)$. Then, Shakuyakukanzoto (0.01 to $0.3 \mathrm{mg} / \mathrm{ml})$ was administrated cumulatively into the bath, and at over $0.1 \mathrm{mg} / \mathrm{ml}$ significantly relaxed the CCh-induced contraction; at 0.3 $\mathrm{mg} / \mathrm{ml}$ by $27.7 \pm 3.3 \%(\mathrm{n}=12, \mathrm{P}<0.001)$. The responses were concentration-dependent. These results are summarized in Table 1.

The relaxation induced by Shakuyakukanzoto $(0.3$ $\mathrm{mg} / \mathrm{ml}$ ) increased (by $37.7 \pm 2.0 \%, \mathrm{n}=8, \mathrm{P}<0.001$ ) at 1 $\mu \mathrm{M}$ nicardipine, but decreased to $15.1 \pm 3.2 \%(\mathrm{n}=5, \mathrm{P}<$ 0.05 ) at $20 \mu \mathrm{M}$ IBMX. Interestingly nicardipine rather 
Table 1. Relaxant effects of shakuyakukanzoto and the components on CCh-induced contraction.

\begin{tabular}{|c|c|c|c|c|c|}
\hline & $\mathrm{n}$ & 0.01 & 0.03 & 0.1 & $0.3 \mathrm{mg} / \mathrm{ml}$ \\
\hline \multicolumn{6}{|c|}{ Shakuyakukanzoto } \\
\hline Control & 12 & $0.2 \pm 0.1$ & $1.8 \pm 1.1$ & $11.1 \pm 2.7^{* * *}$ & $27.7 \pm 3.3^{* * *}$ \\
\hline Nicardipine $1 \mu \mathrm{M}$ & 8 & $1.0 \pm 0.5$ & $11.5 \pm 2.7^{*}$ & $21.8 \pm 2.3^{* *, \#}$ & $37.7 \pm 2.0^{* * *, \#}$ \\
\hline IBMX $20 \mu \mathrm{M}$ & 5 & $0 \pm 0$ & $0 \pm 0$ & $6.0 \pm 2.6^{\# \#}$ & $15.1 \pm 3.2^{*, \#}$ \\
\hline \multicolumn{6}{|l|}{ Paeoniae Radix } \\
\hline Control & 8 & $2.3 \pm 1.3$ & $4.3 \pm 2.8$ & $10.5 \pm 4.5^{* *}$ & $27.3 \pm 6.3^{* *}$ \\
\hline Nicardipine $1 \mu \mathrm{M}$ & 6 & $1.1 \pm 0.4$ & $9.6 \pm 2.4^{*, \#}$ & $13.6 \pm 3.2^{*}$ & $25.4 \pm 2.6^{* *}$ \\
\hline IBMX $20 \mu \mathrm{M}$ & 6 & $0 \pm 0$ & $0 \pm 0$ & $10.4 \pm 2.3^{*}$ & $24.7 \pm 3.3^{* *}$ \\
\hline \multicolumn{6}{|c|}{ Glycyrrhiziae Radix } \\
\hline Control & 8 & $0 \pm 0$ & $0 \pm 0$ & $5.6 \pm 1.8^{*}$ & $19.2 \pm 2.2 * * *$ \\
\hline Nicardipine $1 \mu \mathrm{M}$ & 6 & $1.3 \pm 0.5$ & $6.4 \pm 1.7^{*, \#}$ & $11.3 \pm 1.5^{*, \#}$ & $20.7 \pm 1.8^{* *}$ \\
\hline IBMX $20 \mu \mathrm{M}$ & 9 & $1.6 \pm 1.0$ & $8.3 \pm 2.5^{* *, \#}$ & $21.2 \pm 2.8^{* *, \#}$ & 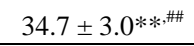 \\
\hline
\end{tabular}

enhanced the relaxation concentration-dependently. Shakuyakukanzoto also did not affect on Bay K 8644 (3 $\mathrm{nM}$ )-induced contraction significantly.

In addition, the relaxation induced by Shakuyakukanzoto $(0.3 \mathrm{mg} / \mathrm{ml})$ was not modified by $100 \mu \mathrm{M}$ suramin, $1 \mu \mathrm{M}$ glibenclamide, and $100 \mathrm{mM}$ tetraethyammonium (TEA). Apamin at $0.1 \mu \mathrm{M}$ attenuated the Shakuyakukanzoton-induced relaxation, but did not cause it to significant extent.

\subsection{Modulation by Paeoniae Radix and Glycyrrhizae Radix}

At $0.01-0.3 \mathrm{mg} / \mathrm{ml}$, the components of Paeoniae radix and Glycyrrhizae Radix relaxed the CCh-induced contraction concentration-dependently (Table 1). Their relaxant effects at $0.1 \mathrm{mg} / \mathrm{ml}$ was $10.5 \pm 4.5 \%(\mathrm{n}=8, \mathrm{P}<$ $0.01)$ and $5.6 \pm 1.8 \%(\mathrm{n}=8, \mathrm{P}<0.05)$, respectively. Glycyrrhizae Radix had the weaker relaxation at all ranges of concentrations.

The relaxation against the CCh-induced contraction was enhanced by nicardipine. The CCh-induced contraction was relaxed by $25.4 \pm 2.6 \%(\mathrm{n}=6, \mathrm{P}<0.01)$ at 0.3 $\mathrm{mg} / \mathrm{ml}$ Paeoniae Radix, but even low concentrations $(0.03 \mathrm{mg} / \mathrm{ml})$ of Paeoniae radix enhanced the relaxation, as compared with the value in the absence of nicardipine. Glycyrrhizae Radix (0.01 to $0.3 \mathrm{mg} / \mathrm{ml})$ also enhanced the relaxation concentration-dependently; at $0.3 \mathrm{mg} / \mathrm{ml}$ by $20.7 \pm 1.8 \%(\mathrm{n}=6, \mathrm{P}<0.01)$.

On the other hand, in the presence of $20 \mu \mathrm{M}$ IBMX, Paeoniae Radix at $0.1 \mathrm{mg} / \mathrm{ml}$ relaxed the CCh-induced contraction by $10.4 \pm 2.3 \%(\mathrm{n}=6, \mathrm{P}<0.05)$. And 0.1 $\mathrm{mg} / \mathrm{ml}$ Glycyrrhizae Radix potentiated the relaxation by
$21.2 \pm 2.8 \%(\mathrm{n}=9, \mathrm{P}<0.01)$. Glycyrrhizae Radix produced the stronger relaxation in the presence of IBMX. These results indicate that both components make minor contribution to the PDE- and $\mathrm{Ca}^{2+}$ channel-dependent relaxations.

\subsection{Effects of Paeoniflorin and Glycyrrhetic Acid}

Paeoniflorin, a constituent of Paeoniae Radix, at 0.1 to 1 $\mathrm{mM}$ relaxed the CCh-induced contraction (Table 2). At $0.3 \mathrm{mM}$, the relaxing effect was $16.3 \pm 6.3 \%$ (n $=4$, $\mathrm{P}<$ 0.05). Glycyrrhetic acid, a constituent of Glycyrrhizae radix, at $0.3 \mathrm{mM}$ also relaxed by $6.4 \pm 2.0 \%(\mathrm{n}=4, \mathrm{P}<$ 0.05). These responses behaved concentration-dependently. Paeoniflorin exhibited a stronger relaxation than glycyrrhetic acid.

Paeoniflorin markedly attenuated the CCh-induced contraction, but not in the presence of nicardipine. The relaxation induced by paeoniflorin $(1 \mathrm{mM})$ was $20.5 \pm$ $2.9 \%(\mathrm{n}=8, \mathrm{P}<0.01)$ at $1 \mu \mathrm{M}$ nicardipine and $4.7 \pm$ $0.4 \%(n=6, P>0.05)$ at $20 \mu \mathrm{M}$ IBMX. Glycyrrhetic acid $(1 \mathrm{mM})$ also relaxed the contraction by $16.4 \pm 2.1 \%$ $(\mathrm{n}=6, \mathrm{P}<0.01)$ at $1 \mu \mathrm{M}$ nicardipine, and by $7.1 \pm 2.7 \%$ $(\mathrm{n}=6, \mathrm{P}>0.05)$ at $20 \mu \mathrm{M}$ IBMX. Both glycyrrhetic acid and paeoniflorin had no $\mathrm{Ca}^{2+}$ channel inhibitory action, but possessed the PDE inhibitory action $(\mathrm{P}<0.05-$ $0.01)$.

\subsection{Effects of 18- $\beta$ - and 18- $\alpha$-Glycyrrhetic Acids}

Metabolic products (bioactive components) of glycyrrhetic acid are 18- $\beta$-glycyrrhetinic acid (a main product) and 18 - $\alpha$-glycyrrhetinic acids. Both products $(0.1$ to 1 
Table 2. Relaxant effects of the constituents and the products from Shakuyakukanzoto on CCh-induced contraction.

\begin{tabular}{|c|c|c|c|c|}
\hline & $\mathrm{n}$ & 0.1 & 0.3 & $1 \mathrm{mM}$ \\
\hline \multicolumn{5}{|l|}{ Paeoniflorin } \\
\hline Control & 4 & $4.1 \pm 1.6^{*}$ & $16.3 \pm 6.3^{*}$ & $19.8 \pm 6.9^{*}$ \\
\hline Nicardipine $1 \mu \mathrm{M}$ & 8 & $6.2 \pm 0.4$ & $14.2 \pm 2.0^{*}$ & $20.5 \pm 2.9 * *$ \\
\hline IBMX $20 \mu \mathrm{M}$ & 6 & $0 \pm 0$ & $1.7 \pm 0.8^{\#}$ & $4.7 \pm 0.4^{\# \#}$ \\
\hline \multicolumn{5}{|c|}{ Glycyrrhetinic acid } \\
\hline Control & 4 & $0.9 \pm 0.6$ & $6.4 \pm 2.0 *$ & $12.1 \pm 3.5^{*}$ \\
\hline Nicardipine $1 \mu \mathrm{M}$ & 6 & $5.1 \pm 2.1^{*, \#}$ & $9.0 \pm 1.7$ & $16.4 \pm 2.1^{* *, \#}$ \\
\hline IBMX $20 \mu \mathrm{M}$ & 6 & $0.8 \pm 0.8$ & $1.7 \pm 1.1^{\# \#}$ & $7.1 \pm 2.7^{\#}$ \\
\hline \multicolumn{5}{|c|}{ 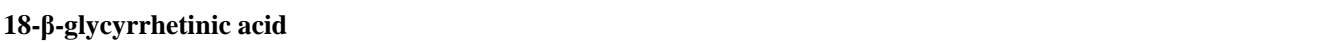 } \\
\hline Control & 8 & $1.4 \pm 1.4$ & $2.5 \pm 1.6$ & $15.1 \pm 6.1^{*}$ \\
\hline Nicardipine $1 \mu \mathrm{M}$ & 11 & $6.7 \pm 1.4$ & $15.8 \pm 4.5^{* *}$ & $25.2 \pm 4.4^{* *}$ \\
\hline IBMX $20 \mu \mathrm{M}$ & 8 & $5.3 \pm 3.6$ & $10.5 \pm 4.3^{*}$ & $18.8 \pm 3.3^{* *}$ \\
\hline \multicolumn{5}{|c|}{ 18-a-glycyrrhetinic acid } \\
\hline Control & 5 & $0 \pm 0$ & $7.0 \pm 2.6$ & $18.6 \pm 3.8^{* *}$ \\
\hline Nicardipine $1 \mu \mathrm{M}$ & 6 & $0 \pm 0$ & $-3.1 \pm 1.9 * *, \# \#$ & $-23.2 \pm 5.0 * *$ \\
\hline IBMX $20 \mu \mathrm{M}$ & 6 & $7.7 \pm 2.1^{*, \#}$ & $12.4 \pm 2.9^{*}$ & $20.5 \pm 3.3^{* *}$ \\
\hline
\end{tabular}

Values (\%) are represented as mean \pm S.E.M. ${ }^{*, \#}: \mathrm{P}<0.05,{ }^{*},{ }^{\# \#}: \mathrm{P}<0.01,{ }^{\# \# \#}$ : $\mathrm{P}<0.001,{ }^{*}$ means a significant difference between the value at each concentration and control value. ${ }^{\#}$ means a significant difference of the values in the presence, as compared with the values in the absence of inhibitors at each concentration.

$\mathrm{mM}$ ) also relaxed the CCh-induced contraction concentration-dependently (Table 2). At $1 \mathrm{mM}$, the relaxing effects of $18-\alpha$ - and 18- $\beta$-glycyrrhetinic acids were 18.6 $\pm 3.8 \%(\mathrm{n}=5, \mathrm{P}<0.01)$ and $15.1 \pm 6.1 \%(\mathrm{n}=8, \mathrm{P}<$ $0.05)$, respectively.

In the presence of $1 \mu \mathrm{M}$ nicardipine, 18 - $\beta$-glycyrrhetinic acid $(1 \mathrm{mM})$ relaxed the CCh-induced contraction by $25.2 \pm 4.4 \%(\mathrm{n}=11, \mathrm{P}<0.01)$, stronger relaxation than control value. On the other hand, 18- $\alpha$-glycyrrhetinic acid $(1 \mathrm{mM})$ caused rather a contraction by $23.2 \pm$ $5.0 \%(\mathrm{n}=6, \mathrm{P}<0.01)$. In the presence of $20 \mu \mathrm{M}$ IBMX, $18-\beta$ - and $18-\alpha$-glycyrrhetinic acids at $1 \mathrm{mM}$ did not affect it; by $18.8 \pm 3.3 \%(\mathrm{n}=8, \mathrm{P}<0.01)$ and by $20.5 \pm$ $3.3 \%(n=6, P<0.01)$, respectively.

\subsection{Effects on Spontaneous Contractions}

Prior administration of CCh $(0.3 \mu \mathrm{M})$ elicited occasionally spontaneous contraction in some specimens (Figure 1(a)). The incidence was in 36 out of 157 specimens (approximately 23\%). Under the condition, application of Shakuyakukanzoto (0.01 to $0.3 \mathrm{mg} / \mathrm{ml})$ depressed the amplitude and prolonged the cycle length of spontaneous contractions (Figures 1(b) and (c)). The depression behaved in a concentration-dependent manner.

\subsection{Effects in the Absence of CCh}

Using rat ileum in non-pretreatment with $\mathrm{CCh}$, the effects of Shakuyakukanzoto and the ingredients on ga- strointestinal smooth muscle were examined. Under the condition, Shakuyakukanzoto $(0.01-0.3 \mathrm{mg} / \mathrm{ml})$ by itself similarly caused the relaxations; at $0.3 \mathrm{mg} / \mathrm{ml}$ by $12.6 \pm$ 3.1\% ( $=13, \mathrm{P}<0.05)$ (Table 3(A)). The components of Paeoniae radix and Glycyrrhizae radix also had similar relaxant actions; at $0.3 \mathrm{mg} / \mathrm{ml}$ by $16.3 \pm 3.6 \%$ ( $\mathrm{n}=12$, $\mathrm{P}<0.001)$ and by $17.5 \pm 3.3 \%(\mathrm{n}=16, \mathrm{P}<0.001)$, respectively. The response was weaker, and was $19.2 \pm$ $2.2 \%(\mathrm{n}=8, \mathrm{P}<0.001)$ at $0.3 \mathrm{mg} / \mathrm{ml}$ in CCh-treated ileum, although the effects of Glycyrrhizae radix were not affected.

At $0.1-1 \mathrm{mM}$, the constituents (paeoniflorin and glycyrrhetic acid) and metabolic products (18- $\beta$ - and $18-\alpha$ glycyrrhetinic acids) similarly relaxed the intestinal smooth muscle concentration-dependently (Table 3(B)). The relaxations induced by paeoniflorin and glycyrrhetic acid at $1 \mathrm{mM}$ were $2.7 \pm 0.9 \%(\mathrm{n}=4, \mathrm{P}<0.05)$ and $5.4 \pm$ $1.0 \%(n=4, P<0.01)$, respectively. And $18-\beta-$ and $18-\alpha$ -glycyrrhetinic acids at $1 \mathrm{mM}$ also decreased by $16.1 \pm$ $4.8 \%(\mathrm{n}=6, \mathrm{P}<0.01)$ and by $14.3 \pm 2.1 \%(\mathrm{n}=4, \mathrm{P}<$ 0.01 ), respectively. The relaxations were observed more markedly in the presence of CCh.

\section{Discussions}

The present experiments showed that Shakuyakukanzoto and its ingredients caused the potent relaxant action on the CCh-induced contraction. They possess anti-cholinergic action. Also the relaxations were due to PDE inhibition or $\mathrm{Ca}^{2+}$ channel inhibition. Shakuyaku- 
Shakuyakukanzoto 0.01

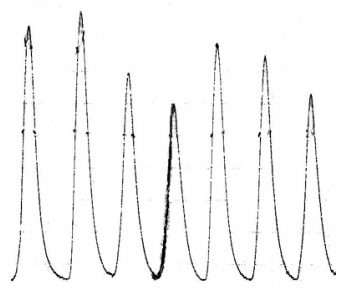

(b)

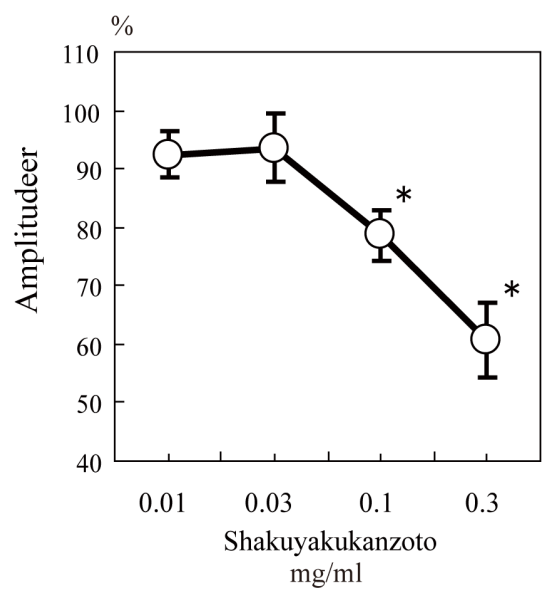

0.03

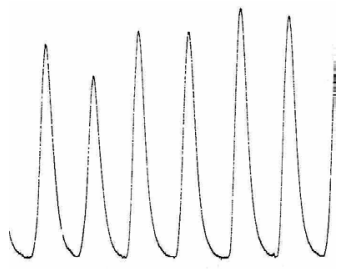

(a)
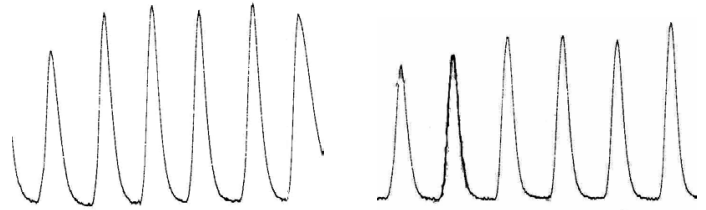

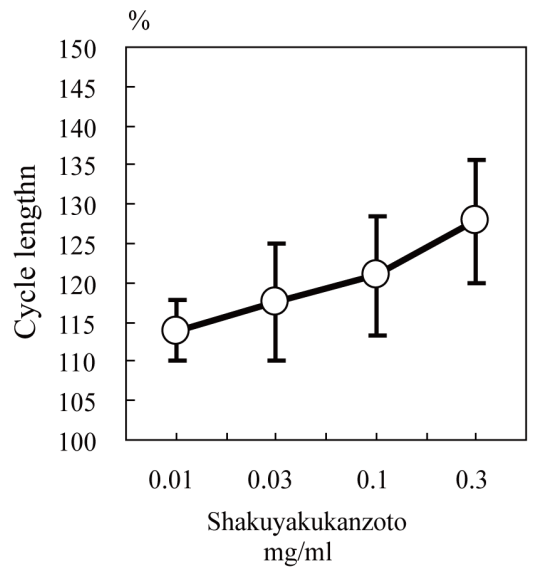

(c)

Figure 1. Spontaneous contractions induced by CCh. (a) Concentration-dependent suppression by Shakuyakukanzoto of the spontaneous contractions. (b) Changes in amplitude of the contractions. (c) Changes in cycle length of the contractions. Values (\%) represent mean \pm S.E.M. *: $\mathbf{P}<0.05, * *$ : $\mathbf{P}<0.01, * * *: P<0.001$, with respect to control value.

Table 3. Comparative relaxing actions of Shakuyakukanzoto, its constituents and the products on the ileum in the absence of $\mathrm{CCh}$.

\begin{tabular}{|c|c|c|c|c|c|}
\hline A & $\mathrm{n}$ & 0.01 & 0.03 & 0.1 & $0.3 \mathrm{mg} / \mathrm{ml}$ \\
\hline Shakuyakukanzoto & 13 & $1.6 \pm 0.3^{*}$ & $3.0 \pm 0.4^{*}$ & $6.3 \pm 1.1^{* *}$ & $12.6 \pm 3.1^{*}$ \\
\hline Paeoniae radix & 12 & $3.3 \pm 0.6^{*}$ & $4.8 \pm 1.8^{*}$ & $8.4 \pm 2.3^{*}$ & $16.3 \pm 3.6^{* * *}$ \\
\hline Glycyrrhizae radix & 16 & $1.6 \pm 0.4$ & $4.8 \pm 0.3^{* *}$ & $11.5 \pm 2.4^{* * *}$ & $17.5 \pm 3.3^{* * *}$ \\
\hline $\mathrm{B}$ & $\mathrm{n}$ & \multicolumn{2}{|c|}{0.1} & 0.3 & $1 \mathrm{mM}$ \\
\hline Paeoniflorin & 4 & \multicolumn{2}{|c|}{$0.2 \pm 0.1$} & $2.8 \pm 0.3^{*}$ & $2.7 \pm 0.9 *$ \\
\hline Glycyrrhetinic acid & 4 & \multicolumn{2}{|c|}{$0.1 \pm 0.2$} & $2.9 \pm 1.0^{*}$ & $5.4 \pm 1.0^{* *}$ \\
\hline 18 - $\beta$-glycyrrhetinic acid & 6 & \multicolumn{2}{|c|}{$2.0 \pm 1.1$} & $2.4 \pm 1.2$ & $16.1 \pm 4.8^{* *}$ \\
\hline $18-\alpha$-glycyrrhetinic acid & 4 & \multicolumn{2}{|c|}{$0.3 \pm 0.2$} & $1.8 \pm 2.4$ & $14.3 \pm 2.1^{* *}$ \\
\hline
\end{tabular}

Values (\%) represent mean \pm S.E.M. *: $\mathrm{P}<0.05$, **: $\mathrm{P}<0.01, * * *$ : $\mathrm{P}<0.001$, with respect to control value.

kanzoto relaxed the intestinal tract even in non-pretreatment with CCh. Occasionally CCh elicited the spontaneous contractions in some specimens, and the application of Shakuyakukanzoto depressed them.

\subsection{Anti-Cholinergic Action}

Prior administration of CCh produced a marked contrac- tion of isolated ileum, consistent with previous report [9]. Shakuyakukanzoto relaxed the CCh-induced contraction. Paeoniae Radix and Glycyrrhizae Radix also relaxed it. At the same concentrations, Shakuyakukanzoto and Paeoniae Radix had stronger relaxing effect than Glycyrrhizae Radix. Even in the absence of CCh, Shakuyakukanzoto itself caused the relaxation and the related compounds also did it, but had much weaker relaxations 
as compared with those in presence of CCh. Glycyrrhizae Radix makes minor contribution to the CCh-induced relaxation, because it also relaxed the ileum without treatment with CCh to almost the same extent.

Paeoniae Radix has been reported to inhibit the contractions induced by nicotine and electric stimulations [3]. The contractions are produced by ACh release from nerve ending mediated through neuroganglionic ACh receptors. Paeoniflorin prevents the damages mediated through muscarinic $\left(\mathrm{M}_{1}\right)$ receptor in rat hippocampal $\left(\mathrm{CA}_{1}\right)$ neurons and ameliorates the dysfunctions $[10,11]$. In the present experiments, both paeoniflorin and glycyrrhetic acid relaxed the CCh-induced contraction. Paeoniflorin had stronger relaxation. $18-\alpha-$ and $18-\beta$-glycyrrhetinic acids also had the concentration-dependent relaxation. These findings indicate that Shakuyakukanzoto and its containing compounds exhibit the anti-cholinergic action, presumably mediated through $\mathrm{M}_{1}$ (or $\mathrm{M}_{3}$ ) receptor. Especially Paeoniae Radix and paeoniflorin in Shakuyakukanzoto possess the stronger anti-cholinergic action.

\section{2. $\mathrm{Ca}^{2+}$ Channel Inhibition}

The inhibition of $\mathrm{Ca}^{2+}$ channel has previously been shown. Paeoniflorin inhibits $\mathrm{Ca}^{2+}$ current in NG108-15 neuronal cells, and $\mathrm{Na}^{+}$current in hippocampus neurons [12], presumably leading to the relaxation of intestinal tract. The inhibition of $\mathrm{Na}^{+}$current results in a decline of cellular $\mathrm{Ca}^{2+}$ concentration $\left(\left[\mathrm{Ca}^{2+}\right]_{\mathrm{i}}\right.$ ) via $\mathrm{Na} / \mathrm{Ca}$ exchange. Paeoniflorin also relaxes the isolated rat aorta due to the $\left[\mathrm{Ca}^{2+}\right]_{\mathrm{i}}$ decline and the increases in NO and cGMP [13].

In the present experiments, however, Shakuyakukanzoto and the containing compounds had no $\mathrm{Ca}^{2+}$ channel inhibitory action. This is supported by the minor action of Shakuyakukanzoto on Bay K 8644 (3 nM)-induced contraction. Interestingly, they decreased the relaxant actions by addition of nicardipine. Only 18- $\alpha$-glycyrrhetinic acid had the inhibitory action of $\mathrm{Ca}^{2+}$ channel, and produced rather the contraction. The mechanisms are now unclear yet, but cellular signaling pathways such as Rho kinase, MLCK and PK-C might be involved [14-17].

Therefore, Shakuyakukanzoto and the related compounds have less or no effect on $\mathrm{Ca}^{2+}$ channel, but might exert the relaxation by the inhibitions of $\mathrm{Na}^{+}$and $\mathrm{K}_{\mathrm{Ca}}$ channels and the activation of cGMP signaling pathway.

\subsection{PDE Inhibition}

Shakuyakukanzoto and the ingredients caused the strong PDE inhibitory action. Especially, Glycyrrhizae Radix, paeoniflorin and glycyrrhetic acid were marked. The PDE inhibition (as a result cAMP accumulation) can produce the potent relaxation of smooth muscle. Most
Kampo formulations have been reported to exert the PDE inhibitory action [5]. The PDE inhibition was observed in paeoniflorin but not in Paeoniae Radix. So, the resultant effects are responsible for an interaction among the containing compounds.

\subsection{Depression of the Spontaneous Contractions and Spasms}

The smooth muscle cells may exhibit the spontaneous contractions. The foundation of pacemaker mechanisms is very similar to that of sino-atrial (SA) nodal cells of heart [18]. It is a pendulum movement with a repetitive depolarization and repolarization. In rat pregnant uterus smooth muscle cells with spontaneous contractions, a hyperpolarization-activated inward (or pacemaker) current $\left(\mathrm{I}_{\mathrm{f}}\right)$, is similarly identified [19]. In general, the spontaneous activity of smooth muscle cells may be largely dependent on transient $\mathrm{Ca}^{2+}$ sparks. Interstitial cells of Cajal, gastrointestinal pacemakers, exhibit $\mathrm{Ca}^{2+}$ release from $\mathrm{IP}_{3}$-dependent $\mathrm{Ca}^{2+}$ stores by activating a $\mathrm{Ca}^{2+}$ dependent cationic current that drives pacemaker depolarization [20]. The $\left[\mathrm{Ca}^{2+}\right]_{\mathrm{i}}$ elevation activates the $\mathrm{K}_{\mathrm{Ca}}$ channels to produce the repolarization of spontaneous action potentials [21], as well as the $\mathrm{Ca}^{2+}$-activated $\mathrm{Cl}^{-}$ channels to produce the depolarization during pacemaker potential [22]. Most recently in guinea pig SA nodal cells, however, we have been found minor contribution of transient $\mathrm{Ca}^{2+}$ sparks [23]. It is not yet clear now, but might be closely related with the connection of $\mathrm{Ca}^{2+}$ channels on the plasma membrane and the sarcoplasmic reticulum (SR) in interstitial smooth muscle.

In this study, after administration of CCh, spontaneous contractions occurred with approximately $23 \%$ incidence. The $\mathrm{K}_{\mathrm{Ca}}$ channel in aortic smooth muscle cells is inhibited by $\beta$-adrenoceptor and muscarinic receptor stimulations and also by PK-C stimulation [24]. Glycyrrhetic acid also inhibits $\mathrm{K}_{\mathrm{Ca}}$ channel [3]. In this study, application of Shakuyakukanzoto ceased the spontaneous contractions. Thus, the depression would be partly due to inhibition of $\mathrm{K}_{\mathrm{Ca}}$ channel and regulation of $\mathrm{Ca}^{2+}$ movement near around neuromuscular junction, because of minor contribution of $\mathrm{Ca}^{2+}$ channel.

In skeletal muscles, nicotinic ACh receptor on neuromuscular junction plays an important role for the contraction. Paeoniflorin produces the relaxation by means of a depolarized blockade like succinylcholine [2]. Paeoniflorin regulates $\mathrm{Ca}^{2+}$ movement near around neuromuscular junction, and glycyrrhetic acid inhibits $\mathrm{K}_{\mathrm{Ca}}$ channel [3]. In rat hippocampal slice, furthermore, the dependence of anti-cholinergic action has been found [10]. The combination with Paeoniae Radix and Glycyrrhizae Radix would enforce the relaxant action of skeletal muscle. Most recent reports have demonstrated that 
Table 4. Pharmacological actions of Shakuyakukanzoto and the ingredients.

\begin{tabular}{lccc}
\hline & Anti-cholinergic action & $\mathrm{Ca}^{2+}$ channel inhibition & PDE inhibition \\
\hline Shakuyakukanzoto & + & - & + \\
Paeoniae radix & + & - & - \\
Glycyrrhiziae radix & - & - & - \\
Paeoniflorin & + & - & + \\
Glycyrrhetinic acid & + & - & - \\
18 - $\beta$-glycyrrhetinic acid & + & + & - \\
18 - $\alpha$-glycyrrhetinic acid & + & & + \\
\hline
\end{tabular}

Shakuyakukanzoto may be sufficiently effective for spasmodic diseases of gastrointestinal tract, as well as for cramp and twitch of skeletal muscle. The antispasmodic and muscle relaxing effects are exerted not only by the anti-cholinergic action (mediated through nicotinic and muscarinic ACh receptors) but also by PDE inhibitory actions. Glycyrrhetic acid and the metabolic products can slow myocardial conduction via modulation of gap junction, but not via that of the ionic channels [25]. Also 18- $\beta$ - and 18- $\alpha$-glycyrrhetinic acids exert a blocking action of gap junction $[6,8]$. The blockade of gap junction prevents spasmodic diseases in gastrointestinal smooth muscle, and reduces epileptogenicity and arrhythmogenesis [7]. Thus, the pharmacokinetic properties may be well suitable for the transient clamp in leg skeletal muscle and the gastrointestinal spasms.

\section{Conclusions}

Shakuyakukanzoto possesses the higher bioactivities for rat ileum, and is so effective for many diseases in clinical uses. Shakuyakukanzoto produced a remarkable relaxation by 1) the anti-cholinergic and 2) the PDE inhibitory actions, but by 3) minor contribution of $\mathrm{Ca}^{2+}$ channel inhibition. Also, Shakuyakukanzoto exerted an antispasmodic action due to the interaction with pharmacological effects of its ingredients.

The absorption is rapid from intestine, and the plasma concentration-time curves are fitted with a mean terminal half-life $\left(\mathrm{T}_{1 / 2}\right)$ of $116.2 \mathrm{~min}$ [26]. Glycyrrhetic and 18- $\beta$ glycyrrhetinic acids possess a free radical scavenging property $[27,28]$, and anti-allergic activities such as passive cutaneous anaphylaxis and skin contact inflammation $[29,30]$. However, the pathological findings of the metabolic products from glycyrrhetic acid have also been well known [31].

Finally, the pharmacological characteristics of Shakuyakukanzoto, the ingredients and the related compounds are summarized on Table 4. Further extensive studies are needed to elucidate in more detail mechanisms.

\section{Acknowledgements}

The authors wish to express thanks for the supply of Shakuyakukanzoto extract (Tsumura Co.).

\section{References}

[1] M. Kimura, I. Kimura, K. Takahashi, M. Muroi, M. Yoshizaki, M. Kanaoka and I. Kitagawa, "Blocking Effects of Blended Paeoniflorin or Its Related Compounds with Glycyrrhizin on Neuromuscular Junctions in Frog and Mouse,” Japanese Journal of Pharmacology, Vol. 36, No. 3, 1984, pp. 275-282. doi:10.1254/jip.36.275

[2] M. Kimura, I. Kimura and H. Nojima, "Depolarizing Neuromuscular Blocking Action Induced by Electropharmacological Coupling in the Combined Effect of Paeoniflorin and Glycyrrhizin," Japanese Journal of Pharmacology, Vol. 37, No. 4, April 1985, pp. 395-399. doi:10.1254/jip.37.395

[3] M. Kimura, I. Kimura and M. Kimura, "Decreasing Effects by Glycyrrhizin and Paeoniflorin on Intracellular $\mathrm{Ca}^{2+}-\mathrm{Ae}-$ quorin Luminescence Transients with or without Caffeine in Directly Stimulated-Diaphragm Muscle of Mouse,” Japanese Journal of Pharmacology, Vol. 39, No. 3, November 1985, pp. 387-390. doi:10.1254/jjp.39.387

[4] J. X. He, E. Goto, T. Akao and T. Tani, "Interaction between Shaoyao-Gancao-Tang and a Laxative with Respect to Alteration of Paeoniflorin Metabolism by Intestinal Bacteria in Rats," Phytomedicine, Vol. 14, No. 7-8, August 2007, pp. 454-459. doi:10.1016/j.phymed.2006.09.014

[5] Y. Saegusa, A. Sugiyama, A. Takahara, Y. Nagasawa and K. Hashimoto, "Relationship between Phoshpodiesterase Inhibition Induced by Several Kampo Medicines and Smooth Muscle Relaxation of Gastrointestinal Tract Tissues of Rats,” Journal of Pharmacology, Vol. 93, No. 1, 2003, pp. 62-68.

[6] Y. Takeda, S. M. Ward, K. M. Sanders and S. D. Koh, "Effects of the Gap Junction Blocker Glycyrrhetinic Acid on Gastrointestinal Smooth Muscle Cells,” American Journal of Physiology, Gastrointestinal Liver Physiology, Vol. 289, No.4, April 2005, pp. G832-G841. doi:10.1152/ajpgi.00389.2004

[7] Z. Gajda, E. Hermesz, E. Gyengesi, Z. Szupera and M. Szente, "The Functional Significance of Gap Junction Channels in the Epileptogenicity and Seizure Susceptibility of Juvenile Rats,” Epilepsia, Vol. 47, No. 6, 2006, pp. 1009-1022. doi:10.1111/j.1528-1167.2006.00573.x 
[8] E. E. Daniel, A. F. EI-Yazbi, M. Mannarino, G. Galante, G. Boddy, J. Livergant and T. E. Oskouei, "Do Gap Junctions Play a Role in Nerve Transmissions as well as Pacing in Mouse Intestine,” American Journal of Physiology, Gastrointestinal Liver Physiology, Vol. 292, No. 3, 2007, pp. G734-G745. doi:10.1152/ajpgi.00428.2006

[9] A. Sugaya, H. Okita, Y. Takazu and E. Sugaya, "Nerupharmacological Study of Saiko-keisi-to,” Shoyaku, Vol. 29, 1975, pp. 160-165.

[10] K. Tabata, K. Matsumoto and H. Watanabe, "Paeoniflorin, a Major Constituent of Peony Root, Reverses Muscarinic $\mathrm{M}_{1}$-Receptor Antagonist-Induced Suppression of LongTerm Potentiation in the Rat Hippocampal Slice,” Japanese Journal of Pharmacology, Vol. 83, 2000, pp. 25-30. doi:10.1254/jjp.83.25

[11] J. Liu, D. Z. Jin, L. Xiao and X. Z. Zhu, "Paeoniflorin Attenuates Chronic Cerebral Hypoperfusion-Induced Learning Dysfunction and Brain Damage in Rat,” Brain Research, Vol. 1089, No. 1, May 2006, pp. 162-170. doi:10.1016/j.brainres.2006.02.115

[12] G. Q. Zhang, X. M. Hao, S. Z. Chen, P. A. Zhou, H. P. Cheng and C. H. Wu, "Blockade of Paeoniflorin on So-

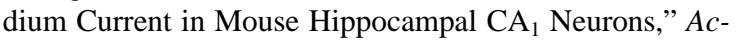
ta Pharmacologica Sinica, Vol. 24, No. 12, December 2003, pp. 1248-1252.

[13] T. Y. Tsai, S. N. Wu, Y. C. Liu, A. Z. Wu and Y. C. Tsai, "Inhibitory Action of L-type $\mathrm{Ca}^{2+}$ Current by Paeoniflorin, a Major Constituent of Peony Root, in NG108-15 Neuronal Cells,” European. Journal of Pharmacology, Vol. 523, No. 1-3, October 2005, pp. 16-24. doi:10.1016/j.ejphar.2005.08.042

[14] K. S. Murthy, Y. S. Yee, J. R. Grider and G. M. Makhlouf, "Phorbol-Stimulated $\mathrm{Ca}^{2+}$ Mobilization and Contraction in Dispersed Intestinal Smooth Muscle Cells," Journal of Pharmacology and Experimental Therapeutics, Vol. 294, No. 3, 2000, pp. 991-996.

[15] K. S. Murthy, J. R. Grider, J. F. Kuemmerle and G. M. Makhlouf, "Sustained Muscle Contraction Induced by Agonists, Growth Factors, and $\mathrm{Ca}^{2+}$ Mediated by Distinct PKC Isozymes," American Journal of Physiology, Gastrointestinal Liver Physiology, Vol. 279, No. 1, July 2000, pp. G201-G210.

[16] F. Nakao, S. Kobayashi, K. Mogami, Y. Mizukami, S. Shirao, S. Miwa, N. Todoroki-Ikeda, M. Ito and M. Matsuzaki, "Involvement of Src Family Protein Tyrosine Kinase in $\mathrm{Ca}^{2+}$ Sensitization of Coronary Artery Contraction Mediated by a Sphingosylphosphorylcholin-Rho-Kinase Pathway,” Circulation Research, Vol. 91, 2002, pp. 952-960. doi:10.1161/01.RES.0000042702.04920.BF

[17] S-K. Ryu, D. S. Ahn, Y-E. Cho, S-K. Choi, Y-H. Kim, K, G. Morgan and Y-H. Lee, "Augmented-Induced $\mathrm{Ca}^{2+}-$ Sensitization of Mesenteric Artery Contraction in Spontaneous Hypertensive Rat," Naunyn-Schmiedeberg Archive of Pharmacology, Vol. 373, No. 1, 2006, pp. 30-36. doi:10.1007/s00210-006-0036-7

[18] H. Satoh, "Sino-Atrial Nodal Cells of Mammalian Hearts: Ionic Currents and Gene Expression of Pacemaker Ionic
Channels,” Journal of Smooth Muscle Research, Vol. 39, No. 5, 2003, pp.175-193. doi:10.1540/jsmr.39.175

[19] H. Satoh, "Identification of Hyperpolarization-Activated Inward Current in Uterine Smooth Muscle Cell during Pregnancy," General Pharmacology, Vol. 26, No. 6, October 1995, pp. 1335-1338.

doi:10.1016/0306-3623(95)00006-M

[20] L. Thomsen, T. L. Robinson, J. C. F. Lee, L. A. Farraway, M. J. G. Hughes, S. W. Andrews and J. D. Huizinga, "Interstitial Cells of Cajal Generate a Rhythmic Pacemaker Current," Nature Medicine, Vol. 4, No. 7, July 1998, pp. 848-851. doi:10.1038/nm0798-848

[21] M. T. Nelson, H. Cheng, M. Rubart, L. F. Santana, A. D. Bonev, H. J. Knot and W. J. Lederer, "Relaxation of Arterial Smooth Muscle by Calcium Sparks,” Science, Vol. 270, No. 5236, October 1995, pp. 633-637. doi:10.1126/science.270.5236.633

[22] R. ZhuGe, S. M. Sims, R. A. Tuft, K. E. Fogarty and J. V. Jr. Walsh, " $\mathrm{Ca}^{2+}$ Sparks Activate $\mathrm{K}^{+}$and $\mathrm{Cl}^{-}$Channels Resulting in Spontaneous Transient Currents in GuineaPig Tracheal Myocytes,” Journal of Physiology (London), Vol. 513, No. 3, December 1998, pp. 711-718. doi:10.1111/j.1469-7793.1998.711ba.X

[23] Y. Himeno, F. Toyoda, H. Satoh, A. Amano, C. Y. Cha, H. Matsumura and A. Noma, "Minor Contribution to Pacemaking in Guinea Pig SA Node,” American Journal of Physiology, Heart Circulation Physiology, Vol. 300, 2011, pp. H251-H261. doi:10.1152/ajpheart.00764.2010

[24] H. Satoh, "Modulation of $\mathrm{Ca}^{2+}$-Activated $\mathrm{K}^{+}$Current by Isoprenaline, Carbachol, and Phorbol Ester in Cultured (and Fresh) Rat Aortic Vascular Smooth Muscle Cells," General Pharmacology, Vol. 27, No. 2, March 1996, pp. 319-324. doi:10.1016/0306-3623(95)02005-5

[25] P. Kojodjojo, P. Kanagaratnam, O. R. Segal, W. Hussain and N. S. Peters, "The Effects of Carbenoxolone on Human Myocardial Conduction: A Tool to Investigate the Role of Gap Junction Uncoupling in Human Arrhythmogenesis," Journal of the American College of Cardiology, Vol. 48, No. 6, September 2006, pp. 1242-1249. doi:10.1016/j.jacc.2006.04.093

[26] L. C. Chen, M. H. Chou, M. F. Lin and L. L. Yang, "Pharmacokinetics of Paeoniflorin after Oral Administration of Dshao-yao Gan-chao Tang in Mice,” Japanese Journal of Pharmacology, Vol. 88, No. 3, 2002, pp. 250 255. doi:10.1254/jip. 88.250

[27] H. Hosseinzadeh, A. M. Nassiri and S. Parvardeh, "The Effects of Carbenoxolone, a Semisynthetic Derivative of Glycyrrhizinic Acid, on Peripheral and Central IschemiaReperfusion Injuries in the Skeletal Muscle and Hippocampus of Rats,” Phytomedicine, Vol. 12, No. 9, September 2005, pp. 632-637. doi:10.1016/j.phymed.2004.07.007

[28] I. G. Sava, V. Battaglia, C. A. Rossi, M. Salvi and A. Toninello, "Free Radical Scavenging Action of the Natual Polyamine Spermine in Rat Liver Mitochondria,” Free Radical Biology and Medicine, Vol. 41, No. 8, October 2006, pp. 1272-1281. doi:10.1016/j.freeradbiomed.2006.07.008 
[29] H. Y. Park, S. H. Park, H. K. Yoon, M. J. Han and D. H. Kim, "Anti-Allergic Activity of 18- $\beta$-Glycyrrhetinic Acid-3-O- $\beta$-D-Glucuronide," Archives of Pharmacal Research, Vol. 27, 2004, pp. 57-60. doi:10.1007/BF02980047

[30] O. H. Kang, J. A. Kim, Y. A. Choi, H. J. Park, D. K. Kim, Y. H. An, S. C. Choi, K. J. Yun, Y. H. Nah, X. F. Cai, Y. H. Kim, K. H. Bae and Y. M. Lee, "Inhibition OH Interleukin-8 Production in the Human Colonic Epithelial Cell
Line HT-29 by $18-\beta$-Glycyrrhetinic Acid,” International Journal of Molecular Medicine, Vol. 15, 2005, pp. 981985.

[31] H. Kato, M. Kanaoka, S. Yano and M. Kobayashi, “3Monoglucuronyl-Glycyrrehetic Acid is a Major Metabolite That Causes Licorice-Induced Pseudoaldosteronism," Journal of Clinical Endocrinology and Metabolism, Vol. 80, No. 6, June 1995, pp. 1929-1933.

\section{Abbreviations}

ACh: acetylcholine

ATP: adenosine triphosphate

ANOVA: analysis of varience

CA: hippocampal neuron

CCh: carbachol

DMSO: dimethyl sulfoxide

$\mathrm{T}_{1 / 2}$ : half-life

IBMX: 3-isobutyl-1-methylxanthine

$\mathrm{I}_{\mathrm{f}}$ : hyperpolarization-activated inward (or pacemaker) current

IL: interleukin

$\mathrm{IP}_{3}$ : inositol triphosphate

$\mathrm{K}_{\mathrm{Ca}}: \mathrm{Ca}^{2+}$-activated $\mathrm{K}^{+}$channel

$\mathrm{M}_{1}$ receptor: muscarinic receptor

MLCK: myosin light chain kinase

PDE: phosphodiesterase

PK-C: protein kinase C

SA node: sino-atrial node

SR: sarcoplasmic reticulum

TEA: tetraethyammonium 